\title{
Correction to: Mutations within FGFR1 are associated with superior outcome in a series of 83 diffuse midline gliomas with H3F3A K27M mutations
}

\author{
Ulrich Schüller ${ }^{1,2,3} \mathbb{D} \cdot$ Peter Iglauer ${ }^{4}$ Mario M. Dorostkar ${ }^{5,6} \cdot$ Christian Mawrin $^{7} \cdot$ Jochen Herms $^{5,6} \cdot$ Armin Giese $^{5}$. \\ Markus Glatzel $^{1}$. Julia E. Neumann ${ }^{1}$ (D)
}

Published online: 9 February 2021

(c) Springer-Verlag GmbH Germany, part of Springer Nature 2021

\section{Correction to: Acta Neuropathologica https://doi.org/10.1007/s00401-020-02259-y}

In the original publication, electronic supplementary files are incorrectly processed and published online. The correct versions of electronic supplementary materials are uploaded to this correction article.

Publisher's Note Springer Nature remains neutral with regard to jurisdictional claims in published maps and institutional affiliations.

The original article can be found online at https://doi.org/10.1007/ s00401-020-02259-y.

\section{Supplementary Information The online version contains} supplementary material available at https://doi.org/10.1007/s0040 1-021-02273-8.

Ulrich Schüller

u.schueller@uke.de

$\triangle$ Julia E. Neumann

ju.neumann@uke.de

1 Institute of Neuropathology, University Medical Center Hamburg-Eppendorf, Hamburg, Germany

2 Department of Pediatric Hematology and Oncology, University Medical Center Hamburg-Eppendorf, Hamburg, Germany

3 Research Institute Children's Cancer Center Hamburg, Hamburg, Germany
Institute of Pathology, University Medical Center Hamburg-Eppendorf, Hamburg, Germany

5 Center for Neuropathology, Ludwig-Maximilians-University, Munich, Germany

6 German Center for Neurodegenerative Diseases, Munich, Germany

7 Institute of Neuropathology, University Hospital Magdeburg, Magdeburg, Germany 